\title{
Visualization of Pulmonic Valve using X-plane on Trans Esophageal Echocardiography
}

\author{
Satoru Fujii and Ivan Iglesias* \\ Department of Anesthesiology, Western University, Canada
}

Submission: March 27, 2018; Published: April 13, 2018

*Corresponding author: Ivan Iglesias, Department of Anesthesiology, London Health Sciences Centre, Western University, 339 Windermere Rd, London, Ontario, Canada N6A 5A5, Email: ivan.iglesias@lhsc.on.ca

\section{Introduction}

Ross procedure has gained popularity in certain expert facilities around the globe. Its advantages include freedom from anti-coagulation and better hemodynamic profile compared with conventional AVR. According to one retrospective study reviewing 306 patients undergoing ROSS procedure [1], the overall survival at 15 years was $88 \pm 3 \%$ that is comparable with the matched population and freedom from valve-related deaths was $96.8 \pm 2 \%$ at 16 years and freedom from auto graft and pulmonary homograft reoperation was $74.5 \pm 4.3 \%$ at 16 years. Enciso et al. [2] published a case report of congenital bicuspid pulmonary valve. They incidentally found out about the anomaly intraoperatively and had to switch to conventional AVR. Since bicuspid pulmonary interrogation of the valve needs to be done pre-operatively. Also, according to the literature, quadricuspid pulmonic valve occurs in approximately 1 in 400 to 1 in 2000 people [3]. Although, unlike bicuspid pulmonic valve, it rarely presents with clinical complications, such as valvular insufficiency or stenosis, its long-term outcome when used for ROSS procedure has never been reported. So far, cardiac MRI and CT scan have been used to diagnose pulmonic anomalies preoperatively, however, echocardiographic interrogation of the pulmonic valve has never been described in detail. Hereby, we present an accurate and reproducible method to interrogate the pulmonic valve using $2 \mathrm{D}$ and 3D transesophageal echocardiography.

valve is associated with early stenotic degeneration, appropriate Description of TEE examination

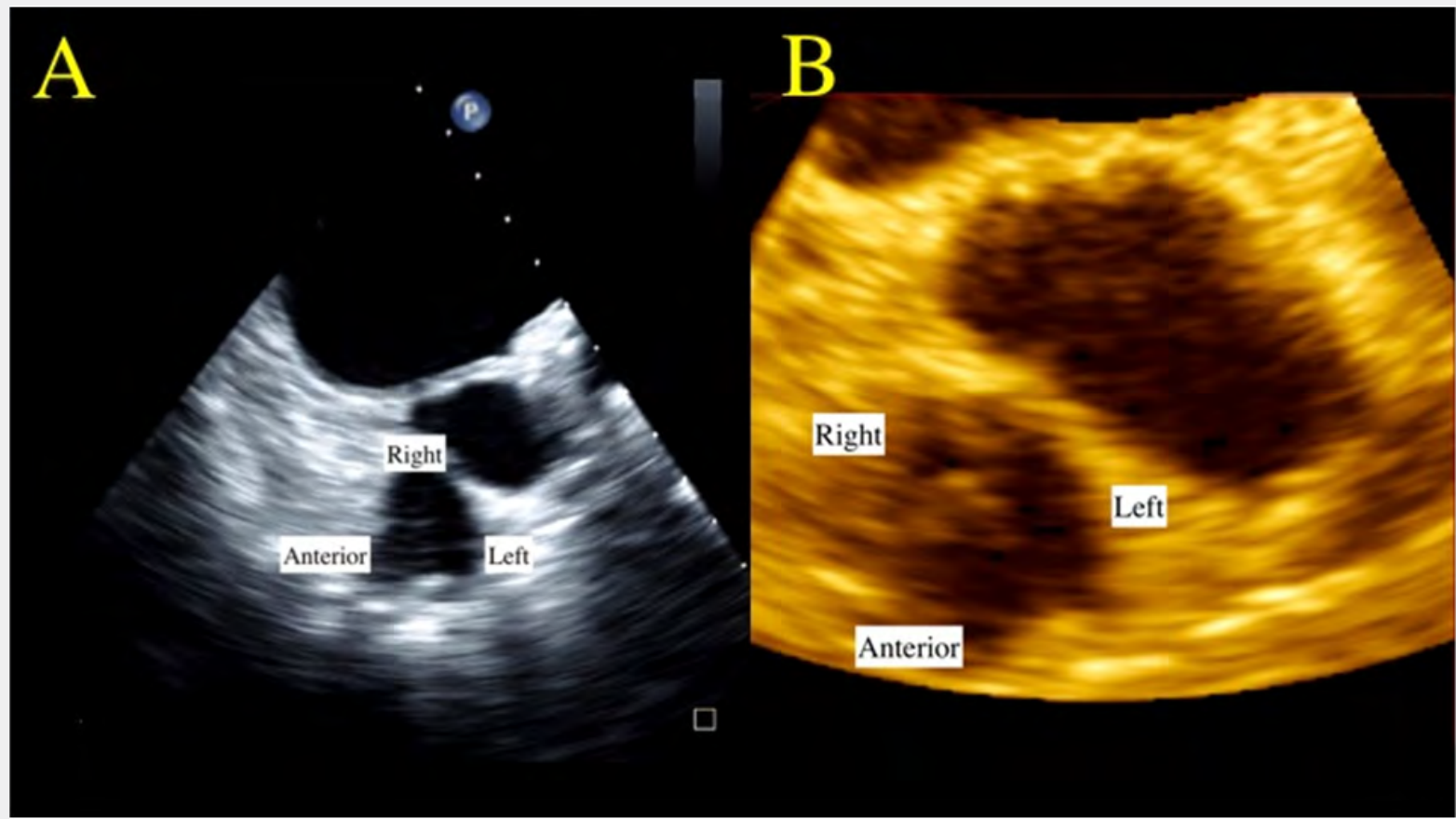

Figure 1: Transesophageal echocardiography (TEE) shows orthogonal views of the pulmonic valve. Three cusps are clearly visualized in the short axis view of the pulmonic valve. 3D TEE view shows 3 cusps of the pulmonic valve more clearly. Anterior, Anterior leaflet; Left, Left leaflet; Right, Right leaflet. 


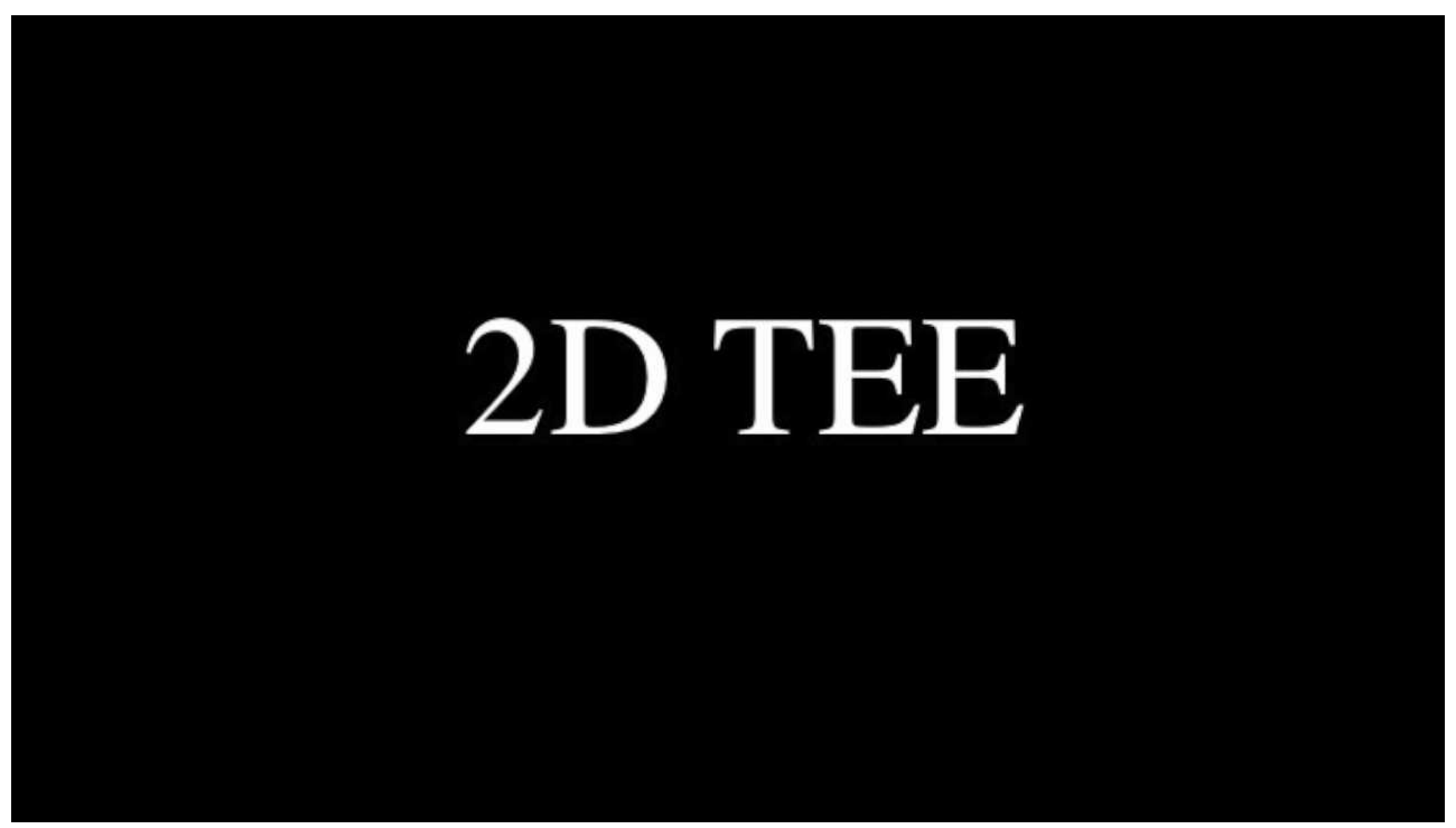

We use iE33 (Philips healthcare, USA) with X7-2t Live 3D TEE probe. Firstly, we adjust the focus position in the far field and switch the setting of frequency to "Pen" mode (low frequency mode). After obtaining the RVOT inflow-outflow view, we put $\mathrm{X}$-plane across the pulmonic valve. By zooming in on the pulmonic valve, the number of cusps and degenerative changes can be observed in a large number of patients (Figure 1, Video). Also, after obtaining a 3D image, pulmonic valve can be cropped out. In this view, the number of cusps can be more clearly assessed. There are some limitations in this method. Firstly, in some patients, pulmonic valve is not well visualized. Appropriate knobs settings help improve image quality in most cases. Secondly, in order to obtain orthogonal views of pulmonic valve, the long axis of the pulmonic valve needs to be in the parallel plane to the cursor. Slight manipulation of the probe (ante or retroflex) helps improve image qualities in this case.

\section{Discussion}

ROSS procedure has gained popularity for its advantages, such as freedom from anticoagulation and comparable long term outcomes. Although the pulmonic valve has never been in the center of attention in the field of cardiac surgery, the growing popularity of ROSS procedure sheds newly light on this under- focused valve. Bicuspid pulmonic valve is associated with fast progression of stenosis and the use of quadricuspid valve as an autograft could be associated with long-term adverse outcomes. Although importance of pre-operative assessment of pulmonic valve has been recognized in ROSS procedure, the proper way has never been reported. The gold standard is considered to be cardiac MRI or multidetector cardiac CT, however, they are not ideal modalities due to high cost and being time consuming. We hereby reported a novel method to interrogate the pulmonic valve. The advantages of our method include cost-effectiveness, high accuracy and easiness to perform. Further studies (i.e. comparison with CT or MRI) are warranted to investigate the reliability of this method.

\section{References}

1. Mastrobuoni S, de Kerchove L, Solari S, Astarci P, Poncelet A, et al. (2016) The Ross procedure in young adults: over 20 years of experience in our Institution. Eur J Cardiothorac Surg 49(2): 507-512.

2. Kajingu Enciso S, Elens M, Rubay J (2017) Congenital bicuspid pulmonary valve. An uncommon impede for Ross procedure. Acta Chir Belg 117(2): 115-117.

3. Dunay SN, Roberge RA, Avedissian LS (2015) Quadricuspid pulmonic valve found on well exam. Mil Med Res 2: 10. 
This work is licensed under Creative Commons Attribution 4.0 License DOI: 10.19080/JAICM.2018.06.555688
Your next submission with Juniper Publishers will reach you the below assets

- Quality Editorial service

- Swift Peer Review

- Reprints availability

- E-prints Service

- Manuscript Podcast for convenient understanding

- Global attainment for your research

- Manuscript accessibility in different formats

( Pdf, E-pub, Full Text, Audio)

- Unceasing customer service

Track the below URL for one-step submission https://juniperpublishers.com/online-submission.php 